warfarin for four months without showing a notable rise in ATIII concentration.

The management of patients with ATIII deficiency is not yet clearly defined. Patients are usually given routine anticoagulant treatment with warfarin sodium unless contraindicated by, for example, peptic ulceration. The age at which treatment should start in people who have not yet sustained an episode of thrombosis but whose ATIII concentrations are known to be low is under debate. Oestrogen-containing contraceptives should be avoided, as oestrogen reduces ATIII concentrations in normal people, though progestogens do not seem to have this effect. The management of pregnancy in affected women presents a major problem. Use of warfarin or related drugs in pregnancy endangers the fetus, though the use of low-dose subcutaneous heparin throughout pregnancy and the early puerperium followed by warfarin treatment might prevent venous thrombosis without presenting a major risk to the fetus. The clinical efficacy of low-dose subcutaneous heparin is, however, unproved in patients with severely reduced plasma ATIII concentrations. A combination of heparin and plasma transfusions during particularly hazardous periods such as surgery or delivery and the early puerperium might also be possible but has not been subjected to trial.

We thank Drs D R Macauley and J A D Goodall and the many family doctors in the west of Scotland; Mr G S Anderson, Royal Northern Infirmary, Inverness; and Dr R Hume, Southern General Hospital, Glasgow: Assays of coagulation inhibitors were carried out by $\mathrm{Mr} \mathrm{M}$ Barbour helped by a grant from the Scottish Home and Health Department.

\section{References}

${ }^{1}$ Lanchantin, G F, et al, Proceedings of the Society for Experimental Biology and Medicine, 1966, 121, 444.

2 Rimon, A, Shamash, Y, and Shapiro, B, fournal of Biological Chemistry, 1966, 241, 5102.
3 Abildgaard, U, Scandinavian fournal of Clinical and Laboratory Investigation, 1967, 20, 207.

4 Yin, E T, Wessler, S, and Stoll, P J, fournal of Biological Chemistry, $1971,246,3703$.

${ }^{5}$ Harpel, P C, and Rosenberg, R D, in Progress in Haemostasis and Thrombosis, vol 3, ed T H Spaet, p 145. New York, Grune and Stratton, 1976.

- Damus, P S, Hicks, M, and Rosenberg, R D, Nature, 1973, 246, 355.

${ }^{7}$ Rosenberg, R D, and Damus, P S, Fournal of Biological Chemistry, 1973, 248, 6490.

${ }^{8}$ Fagerhol, M K, and Abildgaard, U, Scandinavian fournal of Haematology, $1970,7,10$.

- Yin, E T, Wessler, S, and Stoll, P J, fournal of Biological Chemistry, 1971, 246, 3712.

10 Biggs, R, et al, British fournal of Haematology, 1970, 19, 283.

11 Zucker, M L, Gomperts, E D, and Marcus, R G, South African Medical fournal, 1976, 50, 1743.

12 von Kaulla, E, and von Kaulla, K N, Lancet, 1970, 1, 36.

13 Sagar, S, et al, Lancet, 1976, 1, 509.

${ }^{14}$ Egeberg, O, Thrombosis et Diathesis Haemorrhagica, 1965, 13, 516.

15 Abildgaard, U, Gravem, K, and Godal, H C, Thrombosis et Diathesis Haemorrhagica, 1970, 24, 224.

${ }^{16}$ von Kaulla, E, and von Kaulla, K N, American fournal of Clinical Pathology, 1967, 48, 169.

${ }^{17}$ Penick, G D, in Thrombosis, ed S Sherry, et al, p 553. Washington, DC, National Academy of Sciences, 1969.

18 Van Der Meer, J, Stoepman-van Dalen, E A, and Jansen, J M S, fournal of Clinical Pathology, 1973, 26, 532.

19 Shapiro, S S, Prager, D, and Martinez, J, Blood, 1973, 42, 1001.

${ }^{20}$ Marciniak, E, Farley, C H, and De Simone, P A, Blood, 1974, 43, 219.

21 Zucker, M L, Metz, J, and Gomperts, E D, South African Medical fournal, 1975, 49, 1425 .

22 Egeberg, O, Thrombosis et Diathesis Haemorrhagica, 1975, 34, 366.

${ }^{23}$ Gruenberg, J C, Smallridge, R C, and Rosenberg, R D, Annals of Surgery, $1975,181,791$.

24 Nagy, I, Losonczy, H, and Szilagyi, C, Folia Haematologica, 1975, 102, 233.

${ }^{25}$ Carvalho, A, and Ellman, L, American fournal of Medicine, 1976, 61, 179.

26 Filip, D J, Eckstein, J D, and Veltkamp, J J, American fournal of Hematology, 1976, 2, 343.

27 Stathakis, N E, et al, Acta Haematologica, 1977, 57, 47. .

${ }^{28}$ Odegard, O R, and Abildgaard, U, Scandinavian Fournal of Haematology, $1977,18,86$.

${ }^{20}$ Sas, G, et al, Thrombosis et Diathesis Haemorrhagica, 1974, 32, 105.

30 Nagy, I, and Losonczy H, Thrombosis et Diathesis Haemorrhagica, 1975, 34, 366.

(Accepted 11 November 1977)

\title{
Blood transfusion and renal allograft survival*
}

\author{
R W BLAMEY, M S KNAPP, R P BURDEN, MAXINE SALISBURY
}

British Medical fournal, 1978, 1, 138-140

\section{Summary and conclusions}

Thirty-two first renal transplantations with cadaveric allografts were reviewed to see how many of the recipients had received blood transfusions preoperatively.

There was a significant difference in transplant survival between patients who had and patients who had not received blood transfusion before transplantation; this difference was entirely due to acute rejection within three months after transplantation in patients who had not received transfusion. Other factors studied had no effect on survival.

*Paper first read by $\mathrm{R}$ W Blamey at the British Transplantation Society Meeting, Spring 1977.

Renal Unit, Nottingham City Hospital, Nottingham NG5 1PB $R$ W BLAMEY, MD, FRCs, consultant surgeon and reader in surgery M S KNAPP, MD, FRCP, consultant physician

R P BURDEN, MB, MRCP, consultant physician

MAXINE SALISBURY, $\mathrm{MB}$, $\mathrm{CHB}$, clinical assistant

\section{Introduction}

Several recent papers have suggested that a blood transfusion given to patients before first renal transplantation with a cadaveric allograft increases the life of the transplant. ${ }^{12} \mathrm{We}$ have therefore reviewed the 32 successive operations of this type carried out at this centre during February 1974 to January 1977 to see whether the recipients had been given a blood transfusion at any time preoperatively. By analysing a small, single-centre series we could examine more easily than in a larger series ${ }^{3}$ other factors that might have influenced graft survival and been associated with the receipt of blood. These other factors are often not considered in larger series.

\section{Patients and methods}

The 32 operations were carried out on 21 men and 11 women and were first transplantations with cadaver kidneys. Immunosuppression was effected with prednisolone and azathioprine in the standard manner. Sixteen of the patients were included in the MRC multicentre trial of antilymphocytic globulin (ALG) (Wellcome), eight being given ALG for the first 10 days after transplantation. Rejection episodes were treated with 1-6 $\mathrm{g}$ of methylprednisolone in $1-\mathrm{g}$ doses 
given over several days. Follow-up was carried out at increasing intervals during the first year.

Records of patients whose grafts survived for more than one year were examined for rejection episodes occurring between three and 12 months after transplantation. We defined rejection episodes as periods of additional treatment after a clinical diagnosis of rejection accompanied by a rise in the serum creatinine concentration and when on subsequent examination the event was still thought to have been due to rejection.

Blood transfusions were given for various reasons in the build-up for transplantation but never to aid graft survival. Some patients had received blood because of illnesses that had occurred before renal failure. Of all the patients given blood, one received only one unit and the remainder between four and 14 units. In most cases stored whole blood was used with no special preparation.

Kidneys were matched for ABO grouping but not for HLA. Fifteen of the 32 kidneys were obtained through the National Organ Matching Service (NOMS), however, so in these there was some element of HLA matching. Preoperative cross-matching for donorspecific cytotoxic antibodies was carried out in 16 cases; none showed a positive cross-match before operation, and no operation was cancelled because of a positive cross-match.

\section{Results}

Observed kidney survival was calculated by a life-table (actuarial) method and compared with the similarly calculated 1975-6 figures from the NOMS. This was to ensure that our overall figures were not noticeably different from those of other British units, and in general they followed the national trend, despite a higher than average rate of patient acceptance for dialysis and transplantation (25 per million population in 1976, compared with 15 per million population for the UK).

The figure shows the effect of blood transfusion on the Nottingham patients. The NOMS results are given for comparison. There was a significant difference in kidney survival in Nottingham between the group that had received transfusion and the group that had not $\left(\chi^{2}=4.8, P<0.05 ; \log\right.$-rank test). The national figures showed a similar result.

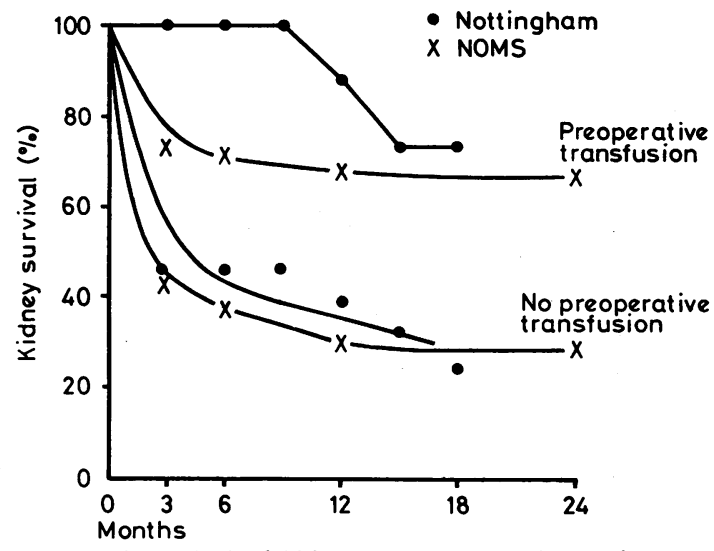

Observed survival of kidneys (first cadaveric renal transplants) in Nottingham series compared with figures from National Organ Matching Service (NOMS) in patients who received and did not receive preoperative blood transfusion.

Five patients died within three months of transplantation. In two of these patients rejection of the kidney was proved histologically; these two kidneys were therefore classed as rejections. Ten other kidneys were rejected, the patients surviving on dialysis: seven were rejected within three months, and three were lost from chronic rejection at 12,15 , and 33 months. None of the nine patients with acute rejection had received preoperative blood transfusion (table I). The difference between the two groups in terms of acute rejection within the first three months was significant. Table II shows the numbers of rejection episodes occurring between three months and one year after transplantation in patients whose transplants survived at one year. There was no significant difference in the numbers of rejection episodes after three months between patients who received
TABLE I-Numbers of patients losing transplants through acute rejection within three months after operation

\begin{tabular}{c|c|c|c}
\hline Group & $\begin{array}{c}\text { No in } \\
\text { group }\end{array}$ & $\begin{array}{c}\text { No losing } \\
\text { transplants }\end{array}$ & $\begin{array}{c}\text { Fisher's } \\
\text { exact test }\end{array}$ \\
\cline { 1 - 2 } $\begin{array}{c}\text { Preoperative blood transfusion } \\
\text { No preoperative blood } \\
\text { transfusion }\end{array}$ & 10 & 0 & $\mathbf{P}=0.035$ \\
\hline
\end{tabular}

TABLE II-Patients with surviving transplants at 12 months: mean number of rejection episodes per patient in each group three to 12 months after operation and mean serum creatinine concentrations and prednisolone dosage in each group at 12 months. Figures are means $\pm S E$ of mean

\begin{tabular}{|c|c|c|c|}
\hline Group & $\begin{array}{l}\text { Mean } \\
\text { No of } \\
\text { rejection } \\
\text { episodes } \\
\text { per patient }\end{array}$ & $\begin{array}{c}\text { Mean } \\
\text { serum } \\
\text { creatinine } \\
\text { concentrations } \\
\text { in each group } \\
(\mu \mathrm{mol} / \mathrm{l})\end{array}$ & $\begin{array}{l}\text { Mean } \\
\text { prednisolone } \\
\text { dose in each } \\
\text { group } \\
\text { (mg/day) }\end{array}$ \\
\hline $\begin{array}{l}\text { Preoperative blood transfusion } \\
\text { ( } 7 \text { patients) } \\
\text { No preoperative blood } \\
\text { transfusion ( } 6 \text { patients) }\end{array}$ & $\begin{array}{l}0.8 \\
0.5\end{array}$ & $\begin{array}{r}90 \cdot 6 \pm 49 \cdot 9 \\
101 \cdot 3 \pm 45 \cdot 3\end{array}$ & $\begin{array}{l}11 \pm 1 \cdot 7 \\
15 \pm 3 \cdot 6\end{array}$ \\
\hline$t$ value & $1.34 ; \mathrm{NS}$ & $0.2 ; \mathrm{NS}$ & $0.9 ; \mathrm{NS}$ \\
\hline
\end{tabular}

NS $=$ Not significant

Conversion: SI to traditional units-Creatinine: $1 \mu \mathrm{mol} / 1 \approx 0.01 \mathrm{mg} / 100 \mathrm{ml}$.

blood before transplantation and those who did not. Serum creatinine concentrations in all patients were recorded one year after transplantation; there was no difference between the groups. The mean prednisolone dosage in both groups after one year was also similar.

Other factors were examined both to show the homogeneity of the two groups and to ensure that the factors themselves did not affect kidney survival. ${ }^{3}$ They included age and sex of the recipient; time spent on haemodialysis before transplantation; match between donor and recipient; haemoglobin concentration of recipient at operation; effect of giving ALG in the first 10 days after transplantation; and effect of blood given during or after transplantation. The groups were homogeneous for age, sex, blood-group matching, and haemoglobin concentrations at operation. Kidney survival was not affected by blood-group matching, HLA matching, or blood transfusion given at or after operation. Of the 15 kidneys that came from other centres, five were given to patients who had received a transfusion. Seven of the 15 were lost within three months of transplantation; this variable therefore had no effect on kidney survival.

Of the kidneys given to the eight patients in the MRC trial who had received ALG after transplantation, only three survived to three months. The difference in kidney survival between these eight patients who received ALG and the 24 who did not was not significant $\left(\chi^{2}=1 \cdot 6\right)$. A similar result (to be reported later) was obtained from the multicentre trial.

\section{Discussion}

In several retrospective series preoperative transfusion of blood to recipients of renal allografts appeared to improve survival of the grafts. Other factors that might have affected rejection, however, were not analysed in detail. ${ }^{3}$ In our series there was a significant difference in kidney survival at both three and 12 months after transplantation between patients who had and patients who had not received blood. This difference was entirely due to the loss of kidneys in the first three months after transplantation in the group that had not received transfusion: of the 22 kidneys in this group, 12 were lost in the first three months, at least nine being lost through acute rejection. No kidney was lost through acute rejection in the transfusion group. After three months the surviving kidneys progressed similarly in the two groups: there were no differences in the numbers of rejection episodes occurring in both groups between three and 12 months, in renal function, or in the dose of immunosuppressive agent needed at 12 months. We found no other factor that might have influenced these results. 
This study, like those reported from other transplant units, did not rely on historical controls but was a retrospective analysis of concurrently treated groups. Haybittle ${ }^{4}$ states that when there is a large difference between two groups in such an analysis the following criteria must be satisfied before acting on the result: the results should be supported by other, similar studies (our study is supported by those referenced and by others); there should be a logical explanation (the phenomenon of immunological enhancement provides this in our case); and there should be experimental backing. ${ }^{5}$

At least one multicentre trial is being established to determine whether preoperative blood transfusion improves graft survival. With such a large difference between the groups, is this multicentre trial necessary or even ethical ? Should units be prepared instead to accept retrospective studies after detailed analysis of the results of the individual units and clinicians has been carried out, and then proceed by giving preoperative transfusions to all patients to see if their results are improved ? Such a study could be historically controlled if no other changes in transplant policy are planned. Peto et $a l^{6}{ }^{6}$ while arguing against historical controls, stated, "if the new treatment cures almost everyone who would previously have died, historical controls may suffice to demonstrate this adequately."

The purpose of this paper is not to make overstrong claims based on a small series of cases but to stimulate other British transplant units to analyse and publish their data on similar lines. The Newcastle unit did so recently, with similar results. ${ }^{7}$ If the great majority of British units found the same trend, with no other factor responsible, then action without a preliminary trial would seem to be the reasonable course. Raising the overall success rate of first cadaver transplants to $75 \%$ by reducing the number of kidneys lost from early acute rejection would overcome many problems.

We thank Dr J Haybittle, department of physics, Addenbrooke's Hospital, Cambridge, for the statistical analysis of our data.

\section{References}

1 National Organ Matching Service, Annual Report (1975-76). Bristol, 1977.

2 Opelz, G, and Terasaki, P I, Lancet, 1974, 2, 696.

3 Knapp, M S, Lancet, 1977, 2, 696.

4 Haybittle, J, personal communication.

${ }^{5}$ Fabre, J W, and Morris, P J, Transplantation, 1972, 13, 608.

${ }^{6}$ Peto, R, et al, British fournal of Cancer, 1976, 34, 585.

7 Uldall, P R, et al, Lancet, 1977, 2, 316.

\title{
Comparison of serum oestrogen concentrations in post-menopausal women taking oestrone sulphate and oestradiol
}

\author{
ANNE B M ANDERSON, E SKLOVSKY, LINDA SAYERS, PENELOPE A STEELE, A C TURNBULL
}

British Medical fournal, 1978, 1, 140-142

\section{Summary and conclusions}

Mean serum concentrations of oestradiol-17 $\beta$, oestrone, and oestrone sulphate in postmenopausal women were the same when measured up to six hours after treatment with either piperazine oestrone sulphate $1.5 \mathrm{mg}$ or oestradiol valerate $2 \mathrm{mg}$. Maximum concentrations of oestradiol were less than those of oestrone, but oestrone sulphate reached concentrations about 30 times higher than those of oestrone.

The rapid conversion of oestradiol valerate to oestrone and oestrone sulphate does not support the suggestion that in menopausal women oestradiol is less likely to be associated with a risk of endometrial carcinoma than oestrone sulphate, since the two preparations appear to become identical after ingestion.

Nuffield Department of Obstetrics and Gynaecology, John Radcliffe Hospital, Headington, Oxford OX3 9DU

ANNE B M ANDERSON, MD, PHD, honorary consultant in clinical reproductive physiology

E SKLOVSKY, medical research assistant

LINDA SAYERS, BSC, research assistant

PENELOPE A STEELE, MSC, medical student

A C TURNBULL, MD, FRCOG, professor

\section{Introduction}

In 1975, reports from the United States ${ }^{12}$ suggested that oestrogen treatment at the time of the menopause might be associated with endometrial carcinoma. Several objections to this were raised, ${ }^{3-5}$ although some reports supported the association. ${ }^{6} 7$ The oestrogen preparation most commonly used in these studies contained conjugated equine oestrogens and a large proportion of oestrone sulphate (Premarin). This together with the "oestrone hypothesis" " namely, that unopposed exposure to oestrone of a target organ such as the endometrium might be causally related to cancer-led to condemnation of the use of oestrogen preparations containing oestrone sulphate for menopausal symptoms. ${ }^{9}$ It was also suggested ${ }^{9}$ that oestradiol and oestriol might be safer alternatives so far as the risk of endometrial carcinoma was concerned. That this might not be true for oestradiol, however, was suggested by Yen et $a l^{10}$ and Jacobs et $a l,{ }^{11}$ who showed that oral micronised oestradiol or oestradiol valerate given to postmenopausal women resulted in circulating concentrations of oestrone greater than those of oestradiol. Although concentrations of oestrone sulphate, a conjugated oestrogen quantitatively the most important circulating oestrogen in premenopausal women, ${ }^{12} 13$ were not measured, it seems likely that they also become greater when oestradiol is ingested, since oestradiol, oestrone, and oestrone sulphate are in equilibrium in the circulation. ${ }^{13} 14$

We tried to resolve the controversy by measuring concentrations of oestradiol, oestrone, and oestrone sulphate in postmenopausal women who were taking oral preparations of either oestrone sulphate (Harmogen; piperazine oestrone sulphate) or oestradiol (Progynova; oestradiol valerate). 